\title{
Experimental Study and Computer Simulation of Fracture Toughness of Ni Base Superalloy Using CT Specimen
}

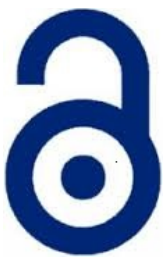 \\ Received: 16 September2018 \\ Accepted: 07 November 2018 \\ Published: 01 December 2018 \\ Publisher: Deer Hill Publications \\ (C) 2018 The Author(s) \\ Creative Commons: CC BY 4.0
}

Muhammad Hasibul Hasan, Chahat Soi, Azin Mirzajavadkhan, Saba Rafieian and Mirt Mehany

\begin{abstract}
Due to superior mechanical and metallurgical performance, Nickel-base Alloys 617 and 276 have been considered as structural material for used in complex and stochastic applications. Surface irregularities such as cracks in the material may be vulnerable to the structural integrity of an engineering component. Void growth behaviour is however analysed using crystal plasticity theory in nickel-based super alloys. Elastic-plastic fracture mechanics base single compact tension specimen has been used to determine the $J_{1 c}$ value as a function of temperature of austenitic Alloy 617 and 276 for ductile crack growth behaviour. Crack formation is appropriately explained through crack nucleation based on the microstructural heterogeneity properties of the alloys. Alloy 617 showed a fair increased resistance to fracture as temperature increased from ambient to $500^{\circ} \mathrm{C}$ for duplicate testing, satisfying the EPFM criteria. Whereas the $\mathrm{J}_{1 \mathrm{C}}$ values of Alloy 276 increased gradually with temperature up to $300^{\circ} \mathrm{C}$ and due to enhanced plasticity in the vicinity of $400^{\circ} \mathrm{C}$ this alloy shows inconsistent value. Two-dimensional simulation of J-integral model of these nickel base super alloys at temperature range $100^{\circ} \mathrm{C}$ to $500^{\circ} \mathrm{C}$ has been proposed. Particular focus is given on the load line displacement where crack propagation occurs during the loading phase only. Path independency of J-integral has been clearly demonstrated for both the alloys up to $300^{\circ} \mathrm{C}$ employing finite element analysis meshing with 1922 quadrilateral 2D solid elements in ANSYS. Cracks are typically initiated in relation to the level of strain range. A higher strain range initiates cracks due to precipitate shearing, whereas a low strain range initiates cracks with oxidation reactions and carbide diffusion. The values of $\mathrm{K}_{1 \mathrm{c}}$ and crack tip opening displacement for these alloys have been calculated based on the experimental data. Moreover, fracture morphology in the loading and unloading sequences near the crack tip has been analysed by SEM.
\end{abstract}

Keywords: Fracture Mechanics, Fracture Toughness, Superalloy, Computer Simulation

\section{INTRODUCTION \\ 1.1 Background}

Due to a disparity in supply and demand, energy price is on the rise. Moreover, excessive use of fossil fuels produces pollutants. For these reasons, researchers are searching for alternative energy sources. Renewable energy is a promising sector as it is clean, available and cheap. Wind is a major source of renewable energy. Wind turbines are used to convert wind energy to electrical power. Currently, worldwide 40,000 MW power is produced from wind energy and it is predicted that the growth rate will be 30\% in the next decade [1]. Alloy 617 and 276 were found appropriate to be used as wind turbine blade material. These alloys are also suitable for heat exchanging applications, such as in Next Generation Nuclear Plants (NGNP) [2]. Therefore, metallurgical characterization of these materials is necessary. Mechanical properties of a structure can be modified in many ways, for example; through the application of annealing, giving Alloy 617 resistance to degradation after long-term exposure [3]. In this paper, the behavior of Alloys 617 and 276 in terms of the metallurgical and mechanical properties are characterized based on the fracture toughness, particularly for wind turbine blade applications along with other conventional polyester glass fiber materials.

M. H. Hasan $\otimes$, C. Soi, A. Mirzajavadkhan, S. Rafieian and M. Mehany

Department of Mechanical and Industrial Engineering

Ryerson University

350 Victoria Street, Toronto, ON M5B 2K3

Canada

Email: hasibulhasan@ryerson.ca

Reference: Hasan, M. H., Soi, C., Mirzajavadkhan, A., Rafieian, S. and Mehany, M. (2018). Experimental Study and Computer Simulation of Fracture Toughness of Ni Base Super Alloys Using CT Specimen. International Journal of Engineering Materials and Manufacture, 3(4), 224-236. 


\subsection{Material Selection}

To be operated in harsh environments such as desert areas where dust and sandstorms are more commonly to happen, turbine blade material should sustain with high impact forces and abrasion. Impact velocity is determined by wind flow velocity and the blade's speed of revolution. Due to the maximization of rotational speed at the leading edges of an aerofoil, an elastomeric material should be applied to prevent erosion. However, it is necessary to replace the tape frequently as they fail to satisfactorily absorb the concussion energy of the particulate matter. Hence, blade materials should be chosen carefully to prevent damages. Polyester-glass fibre blade material is suitable for high impact erosion. However, nickel-based superalloy has the potential to be used as it has a high tensile strength as well as corrosion resistance properties.

In 1970, Ni-base Alloy 617 was developed to be used in aerospace engineering as an advanced sheet material. The significant properties of this alloy are high strength, oxidation resistance at high temperature $\left(980^{\circ} \mathrm{C}\right)$ as well as high resistance to both creep deformation and ruptures at temperatures up to $850^{\circ} \mathrm{C}$ [4]. In addition, it has excellent metallurgical stability and low density, which provides a high strength-to-weight ratio. Due to its oxidation resistance characteristics, Alloy 617 along with Alloy 276 are used in the production process of Nitric Acid, heat treating baskets and reduction boats in molybdenum refinement as catalyst-grid support [5]. Some other high-temperature applications of Alloy 617 are inducting, combustion cans, transition liners in gas-turbines, thermal energy storage capsules, manufacturing of retort furnace and gas cooled reactors. NASA has been using this Alloy material for heat shielding in space transportation systems.

\subsection{Scope}

An examination on tensile deformation of Alloy 617 and 276 under extensive variety of temperatures beginning from ambient to $1000^{\circ} \mathrm{C}$ had been completed by numerous agents [6]. Surface irregularities impact the basic integrity of metallic components. Control variables of development rate of surface irregularities and voids comprise of stress triaxiality, the underlying void volume fraction, lode parameters, the crystallographic orientation, the initiated slip system and the level of elastic anisotropy [7]. Variable stacking conditions are forced on these segments in temperamental desert conditions and dust storms. Elastic-Plastic-Fracture- mechanics (EPFM) was applied to appraise crack durability (fracture toughness) of this alloy at various temperatures [8], which happen contingent upon microstructural heterogeneities and the effect on behaviour-elastic anisotropy, morphology and crystallography with the idea of the enforced loading [9]. Numerical analysis has been finished by business programming ANSYS utilizing Finite element technique, in which conduct of crack deformations are delineated based microscopic and macroscopic structures in impact temperature reliance of yield strength [10]. In an investigation, specimens were tried by scanning electron microscopy (SEM) to decide the morphology of deficiency.

\section{EXPERIMENTATION}

\subsection{Test Material}

Alloy 617 was custom-melted at the Huntington Alloys Corporation, West Virginia by vacuum-induction-melting (VIM). Rectangular and round bars were fabricated using forging and hot-rolling. After the hot-rolling operation, the thickness of rectangular bars was reduced by cold-rolling. However, residual stresses were developed from hot and cold rolling operations, which were relieved further by thermal treatment. This thermal treatment consisted of solution-annealing at $2150^{\circ} \mathrm{F}\left(1175^{\circ} \mathrm{C}\right)$ for variable time periods depending on the thickness of the processed bars. It produces large sized austenitic grains in alloys. After heat treatment by solution-annealing at $1163^{\circ} \mathrm{C}\left(2125^{\circ} \mathrm{F}\right)$, rapid cooling was done which provides a fully austenitic microstructure. Table 1 and 2 provides the chemical composition and room temperature tensile properties of the material, respectively.

Table 1: Chemical Composition of Alloy 617 (HV1160) and 276 (Z7437CG) (wt \%)

\begin{tabular}{lllllllllllll}
\hline Heat No. & $\mathrm{C}$ & $\mathrm{Mn}$ & $\mathrm{Fe}$ & $\mathrm{S}$ & $\mathrm{Si}$ & $\mathrm{Cu}$ & $\mathrm{Cr}$ & $\mathrm{Ni}$ & $\mathrm{Al}$ & $\mathrm{Ti}$ & $\mathrm{Co}$ & $\mathrm{Mo}$ \\
\hline HV1160 & 0.06 & 0.121 & 0.002 & 0.009 & 0.004 & 0.001 & 22.10 & 54.80 & 0.87 & 0.29 & 12.17 & 9.52 \\
Z7437CC & 0.006 & 0.42 & 5.9 & 0.001 & 0.008 & - & 15.8 & 58.3 & - & - & 0.1 & 15.9 \\
\hline
\end{tabular}

Table 2: Ambient-Temperature Tensile Properties

\begin{tabular}{|c|c|c|c|c|c|}
\hline Heat No. & $\begin{array}{l}\text { Yield strength } \\
\qquad \mathrm{MPa}\end{array}$ & $\begin{array}{l}\text { Ultimate tensile strength, } \\
\qquad \mathrm{MPa}\end{array}$ & $\%$ El & $\%$ RA & $\begin{array}{l}\text { Hardness } \\
\quad\left(R_{B}\right)\end{array}$ \\
\hline HV 1160 & 371 & 855 & 78.35 & 61.98 & 86.8 \\
\hline Z7437CG & 354 & 794 & 87 & 60 & 79 \\
\hline
\end{tabular}




\subsection{Test Specimens}

Fracture toughness $\left(J_{1 C}\right)$ of the alloy was determined by a compact-tension $(C T)$ specimen of 25.4 mm thickness with a straight through notch. In the machining process, the longitudinal rolling direction was normal to the crack plane. Figure 1. describes the configuration and pictorial view of the test specimen.

\subsection{Test Procedure}

Test specimens and experimental setup were done as per the procedure prescribed by the ASTM Designation E 313 1989 [12]. Initially, test specimens were designed to evaluate the plane strain fracture toughness [11] based on the linear-elastic fracture- mechanics (LEFM) concept for Alloy 617 [12]. to comply with the LEFM criteria significantly ticker 20" compact tension (CT) specimens were desired and from practical standpoint it was not feasible at all. Specimens cost, machine grip, test machine max, pulling capacity and furnace chamber dimensions would not permit this thick specimen to test. Thus, to evaluate the fracture toughness in terms of $J_{1 c}, 1$ inch thick multiple $C T$ specimens were tested using elastic- plastic- fracture- mechanics (EPFM) concept. For high strength superalloys like Alloy 617, two types of testing methods exist, namely single- specimen technique and multiple- specimen technique. Five specimens were needed for multiple specimen technique but only one specimen was required for single specimen technique to determine $\mathrm{J}_{1 \mathrm{C}}$ value in a particular test temperature. All tests were conducted using single specimen technique at temperature ranging from ambient to $500^{\circ} \mathrm{C}$. Instron testing machine (max capacity of $100 \mathrm{kN}$ ) and $\mathrm{J}_{1 \mathrm{C}}$ fracture toughness software [13] provided by Instron Corporation was used to calculate and validate the fracture toughness value in terms of $J_{1 C}$.

The compact tension specimen was pre-cracked to an approximate of $3 \mathrm{~mm}$ at room temperature using a load ratio(R) of 0.1 and frequency of $1 \mathrm{~Hz}$. Maximum load for pre-cracking was maintained at $20 \mathrm{KN}$ and number of cycle for pre-crack tanged from 55000 to 70000 . Just after pre-cracking, CT specimens was subjected to 30 loading and unloading cycles to measure load line displacement (LLD) or crack opening displacement (COD). Maximum travel distance of a high temperature knife- edge extensometer was kept $\pm 2 \mathrm{~mm}$ to measure the gap between the precracked specimens. Experimental setup and a standard load versus LLD plot is shown in the Figure 2 and 3 respectively.

The shaded area in Figure 3(b) under the curve represents the energy ( $\mathrm{J}$ - integral) required to cause each increment of crack length. Fracture toughness value in terms of J-integral for each small area was calculated using the following equations.

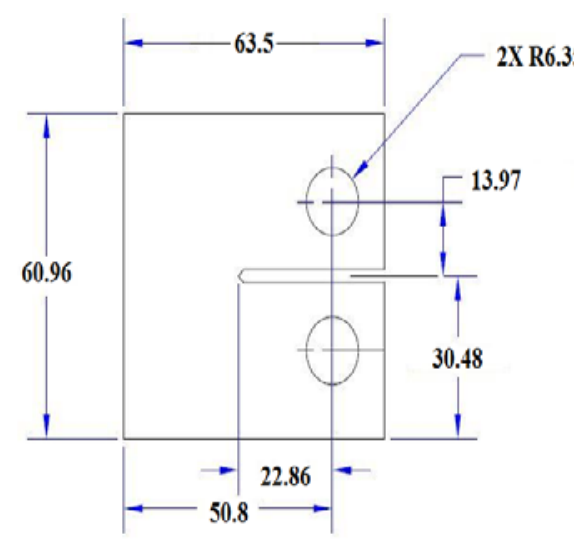

a

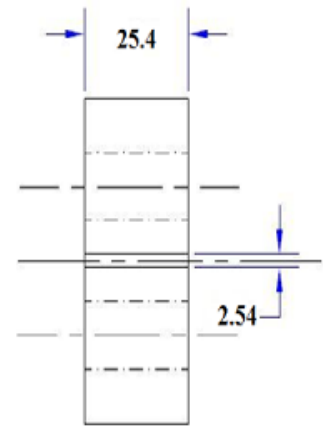

Figure 1: 25.4 mm CT Specimen (a) Specimen Dimensions and (b) Pictorial View

The J-Integral value for each area was calculated using Equations 1-3, given below [12, 14].

$$
\begin{gathered}
\mathrm{J}=\mathrm{J}_{\text {elastic }}+\mathrm{J}_{\text {plastic }} \\
\boldsymbol{y}_{\text {elastic }}=\frac{\mathrm{K}^{2}}{\mathrm{E}}[1-2] \\
\mathrm{J}_{\text {plastic }}=\frac{\eta_{\mathrm{pl}}}{\mathrm{Bb}} \int_{0}^{\mathrm{vpl}} \mathrm{Pdv} \mathrm{pl}_{\mathrm{pl}}=\frac{\eta_{\mathrm{pl}}}{\mathrm{Bb}} \times \mathrm{A}_{\mathrm{pl}}
\end{gathered}
$$




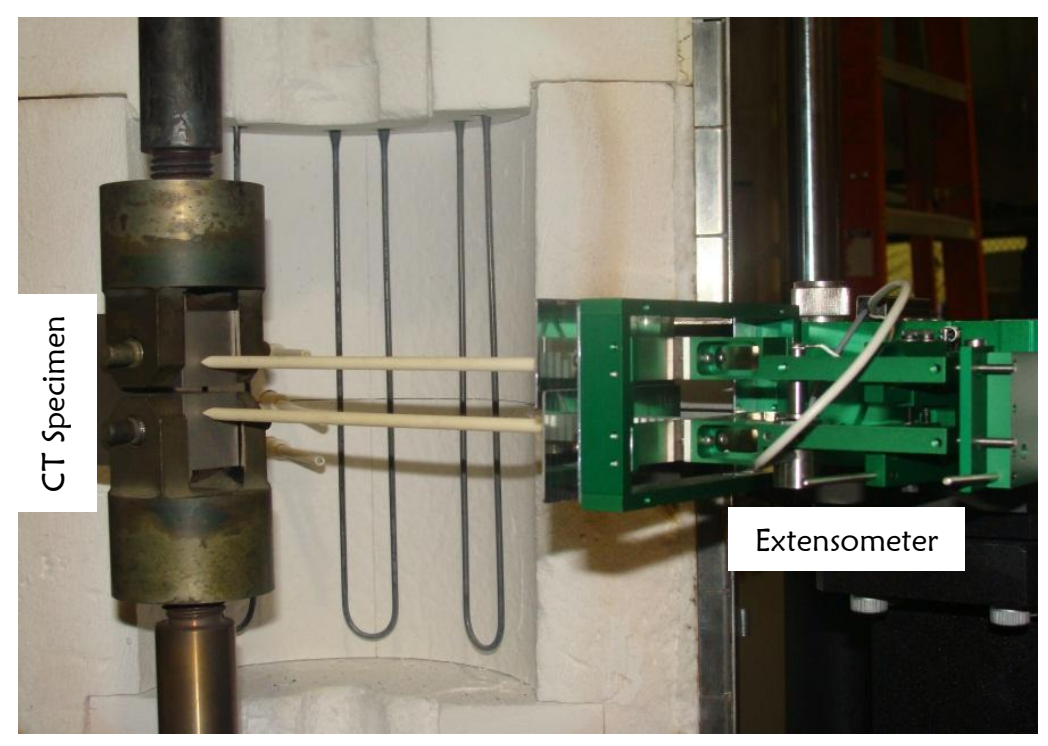

Figure 2: $J_{1 C}$ Test Set-up

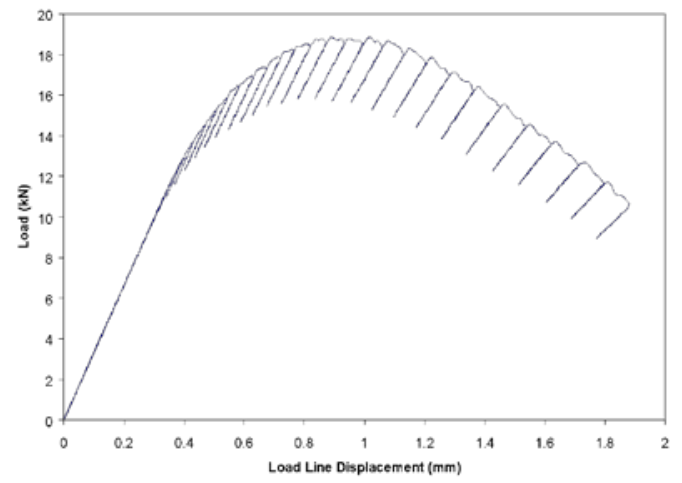

a

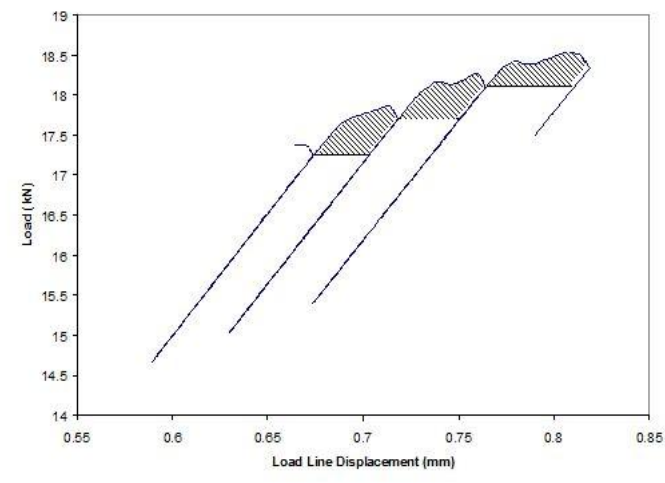

b

Figure 3: (a) Load versus LLD Plot and (b) Areas Representing J-Integral

where

$\mathrm{K}=$ Stress intensity factor, $\mathrm{MPa} \sqrt{\mathrm{m}}=$ $\left[\frac{\mathrm{P}}{\left(\mathrm{BB}_{\mathrm{N}} \mathrm{W}\right)^{0.5}}\right] \propto$

$\mathrm{P}=$ Load, $\mathrm{N}$

$B=$ Specimen thickness, $\mathrm{mm}$

$\mathrm{B}_{\mathrm{N}}=$ Net specimen thickness, $\mathrm{mm}=\mathrm{B}$, in present study

$W=W i d t h$ of the $C T$ specimen, $\mathrm{mm}$

$\alpha=$ Geometric factor of the CT specimen

$\mathrm{E}=$ Elastic modulus of the material

$v=$ Poisson's ratio of the material, 0.3

$\mathrm{b}=$ Uncracked ligament, $\mathrm{mm}$

$\eta_{\mathrm{pl}}=2+0.522 \mathrm{~b} / \mathrm{W}$

$\mathrm{v}_{\mathrm{pl}}=\mathrm{LLD} / \mathrm{COD}, \mathrm{mm}$

$A_{p l}=$ Area corresponding to each loading / unloading sequence $\left(\mathrm{mm}^{2}\right)$ 
The combined elastic and plastic value of $\mathrm{J}$ then plotted against crack extension as shown in Figure 4 Loading compliance principle was used to evaluate each sequence of crack extension $\left(a_{i}\right)$. The following compliance equation 4 was used for $a_{i}$ calculation [12].

$a_{i} / W=1.000196-4.06319 u_{L L}+11.242 u_{L^{2}}{ }^{2}-106.043 u_{L}{ }^{3}+464.335 u_{L}{ }^{4}-650.677 u_{L L}{ }^{5}$

where

$\mathrm{u}_{\mathrm{LL}}=\frac{1}{\left[\mathrm{~B}_{\mathrm{e}} \mathrm{EC}_{\mathrm{i}}\right]^{0.5}+1}$

$B_{e}=$ Effective thickness of the $C T$ specimen, $m m=\left[B-\left(B-B_{N}\right)^{2} / B\right]=B$ (since $\left.B=B_{N}\right)$, in current study

$C_{i}=$ Specimen load line elastic compliance on an unloading/reloading sequence $(\Delta v / \Delta P), m m / N$

$\Delta v=$ Increment in LLD/COD, $\mathrm{mm}$

$\Delta \mathrm{P}=$ Change in load, $\mathrm{N}$

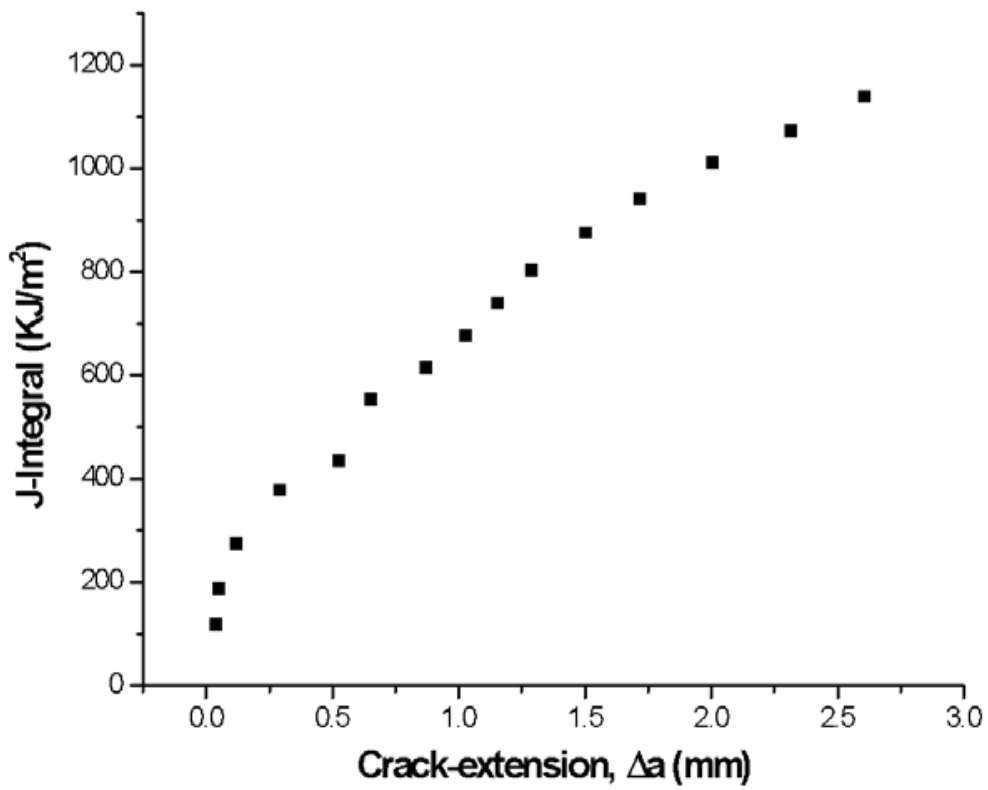

Figure 4: J-Integral vs. Crack-Extension

A power law regeneration curve was plotted in the J-integral versus crack extension $(\Delta a)$. Four parallel lines including blunting line, $0.15 \mathrm{~mm}$ exclusion line, $0.2 \mathrm{~mm}$ exclusion line and $1.5 \mathrm{~mm}$ exclusion line were superimposed on the plot to find the calculated value of $\mathrm{J}$ integral. The plotted value of J- $\Delta a$ can be considered valid if at least one J- $\Delta a$ point lines between $0.15 \mathrm{~mm}$ exclusion line and blunting line. The intersection of the $0.2 \mathrm{~mm}$ exclusion line and regression curve usually represents the $J_{Q}$ or conditional $J_{I C}$ value as shown in the Figure 5 . Usually $J_{Q}$ or the conditional $\mathrm{J}_{1 \mathrm{C}}$ value is considered to be the $\mathrm{J}_{1 \mathrm{C}}$ value if the following two criteria are met:

- Thickness $(B)$ of the specimen $>\left[25 \mathrm{~J}_{\mathrm{Q}} / \sigma_{\gamma}\right]$, where $\sigma_{\gamma}=$ effective yield strength of the material $=$ average of the yield and ultimate tensile strength ( $\sigma_{Y s}$ and $\sigma_{U T S}$, respectively) of the material $=\left[\sigma_{Y S}+\sigma_{U T S}\right] / 2$. Initial uncracked ligament $\left(\mathrm{b}_{0}\right)>\left[25 \mathrm{~J}_{\mathrm{Q}} / \sigma_{\mathrm{Y}}\right]$

- Efforts have also been made to correlate $J_{1 c}$ to $K_{1 c}$. Literature $[15,16]$ suggests that $K_{1 c}$ can be calculated from the $J_{1 c}$ value, according to Equation 5, as given below. Fracture toughness can also be measured using the crack-tip-opening-displacement (CTOD) method, which is based on Equation 6, given below [16]. 


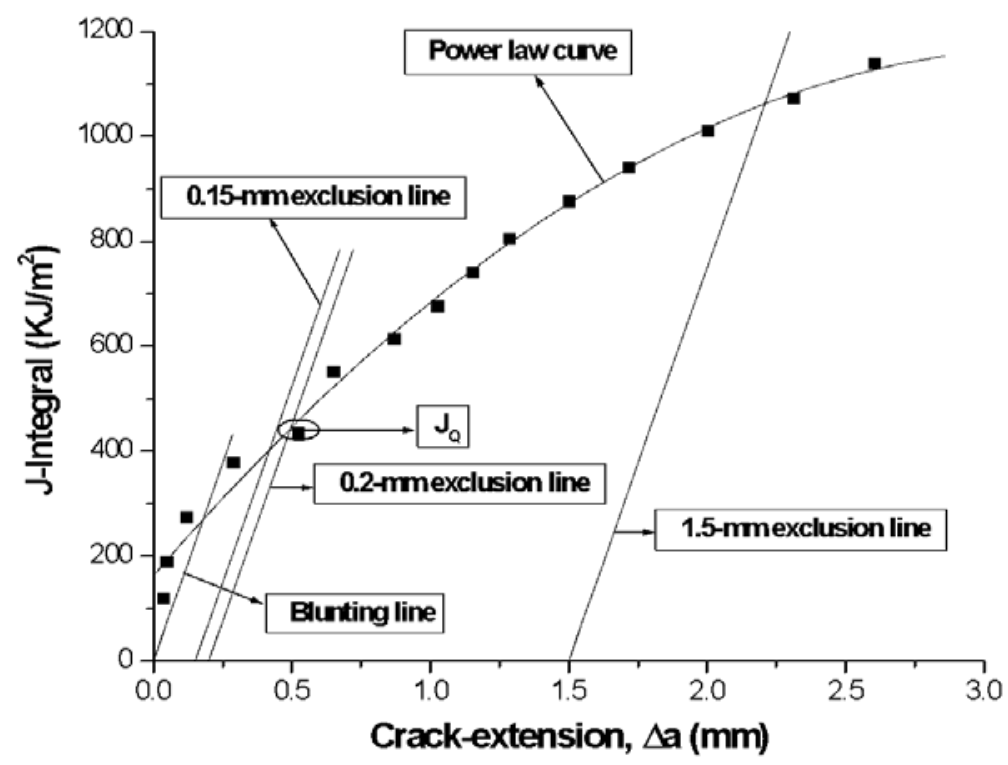

Figure 5: Determination of $\mathrm{J}_{\mathrm{Q}}$ Using J-Integral versus $\Delta$ a Plot

where

$$
\begin{gathered}
\mathrm{K}_{1 \mathrm{C}}=\sqrt{\mathrm{J}_{1 \mathrm{C}} \times \mathrm{E} /\left(1-{ }^{2}\right)} \\
\delta=\frac{\mathrm{K}_{1}^{2}}{\mathrm{mE}}
\end{gathered}
$$

$\delta=$ CTOD, $\mathrm{mm}$

$\mathrm{K}_{1}=\mathrm{K}_{1 \mathrm{c}}$ value of the material, $\mathrm{MPa} \sqrt{\mathrm{m}}$

$\mathrm{m}=$ Constant $=2$ for plane-strain condition

Further, tearing modulus has been calculated based on the flow stress and taking into consideration the slopes of the J-integral vs. crack extension curves.

$$
\begin{gathered}
\sigma_{f}=\frac{1}{2}\left(\sigma_{y}+\sigma_{U T S}\right) \\
T=\frac{E}{\sigma_{f}^{2}} \cdot \frac{d J}{d a}
\end{gathered}
$$

Where,

$\sigma_{f}=$ Flow strength

$\sigma_{y}=$ Yield strength

$\sigma_{U T S}=$ Ultimate tensile strength

$E=$ Young's modulus

$\frac{d J}{d a}=$

The slope of the J-integral vs. crack extension curve 


\section{RESULTS}

\section{$3.1 J_{1 C}$ values}

The validity criteria set by the ASTM Designation E 813-1989 was maintained in the $\mathrm{J}_{1 \mathrm{C}}$ testing procedure. JQ values were obtained from it. In Figure 6., average $\mathrm{J}_{1 \mathrm{C}}$ values are shown for temperature ranging from $30^{\circ} \mathrm{C}$ to $300^{\circ} \mathrm{C}$. It is observed that $\mathrm{J}_{1 \mathrm{C}}$ values decrease with increasing temperature. The effect is higher for temperature up to $100^{\circ} \mathrm{C}(156$ to $103 \mathrm{~kJ} / \mathrm{m}^{2}$ ). However, from $200^{\circ} \mathrm{C}$ to $300^{\circ} \mathrm{C}$, the decrement is insignificant ( 88 to $86 \mathrm{~kJ} / \mathrm{m}^{2}$ ). Figure 7. displays a load vs. LLD plot and a J-Integral vs. $\Delta$ a plot is shown in Figure 8.

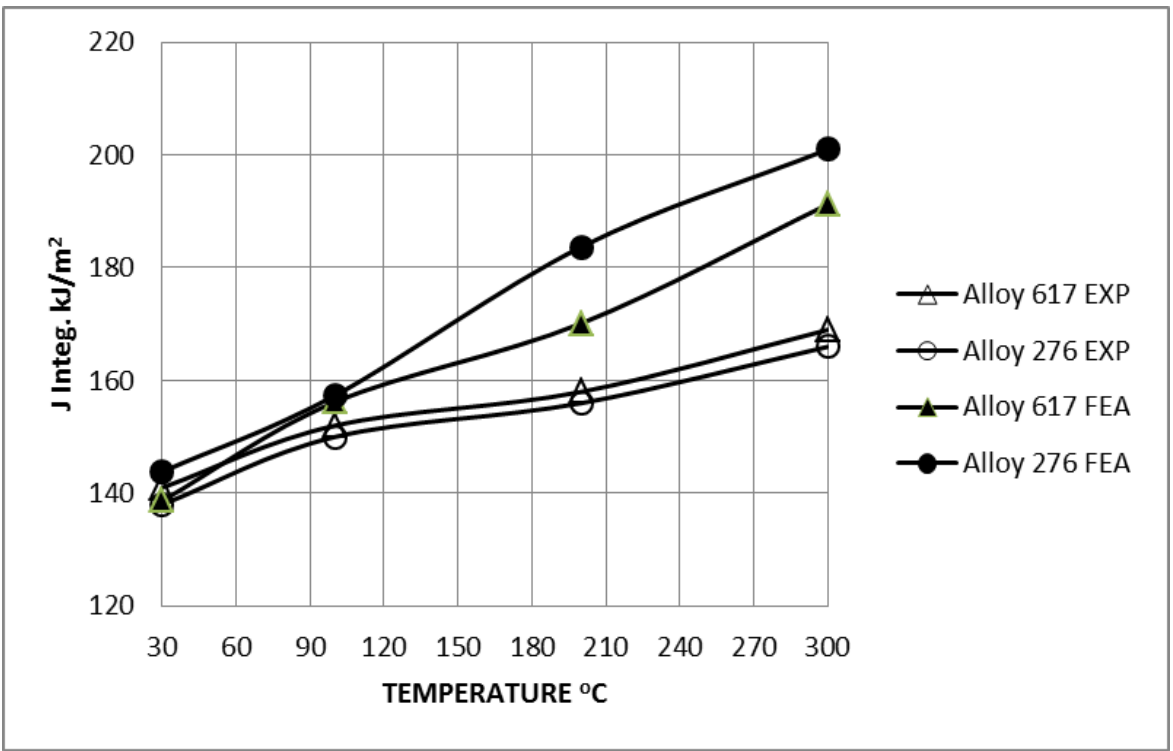

Figure 6: Jic vs. Temperature

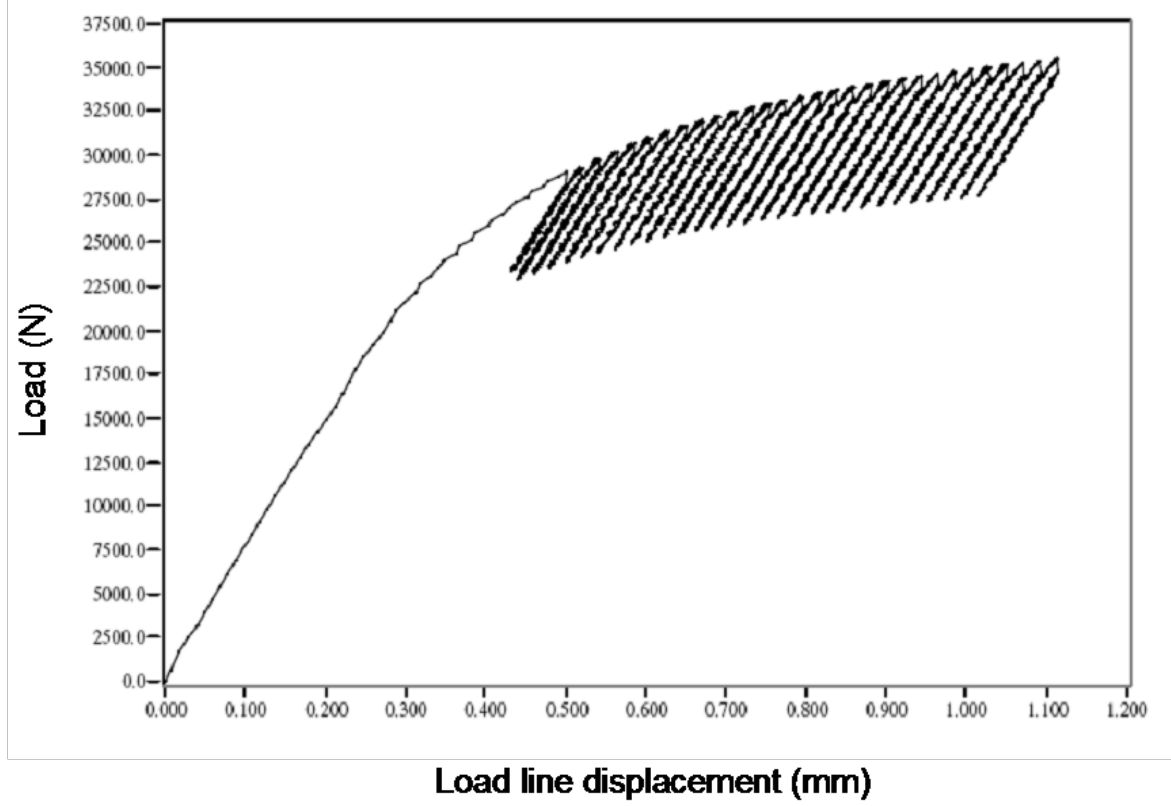

Figure 7: Load vs. LLD at Ambient Temperature 


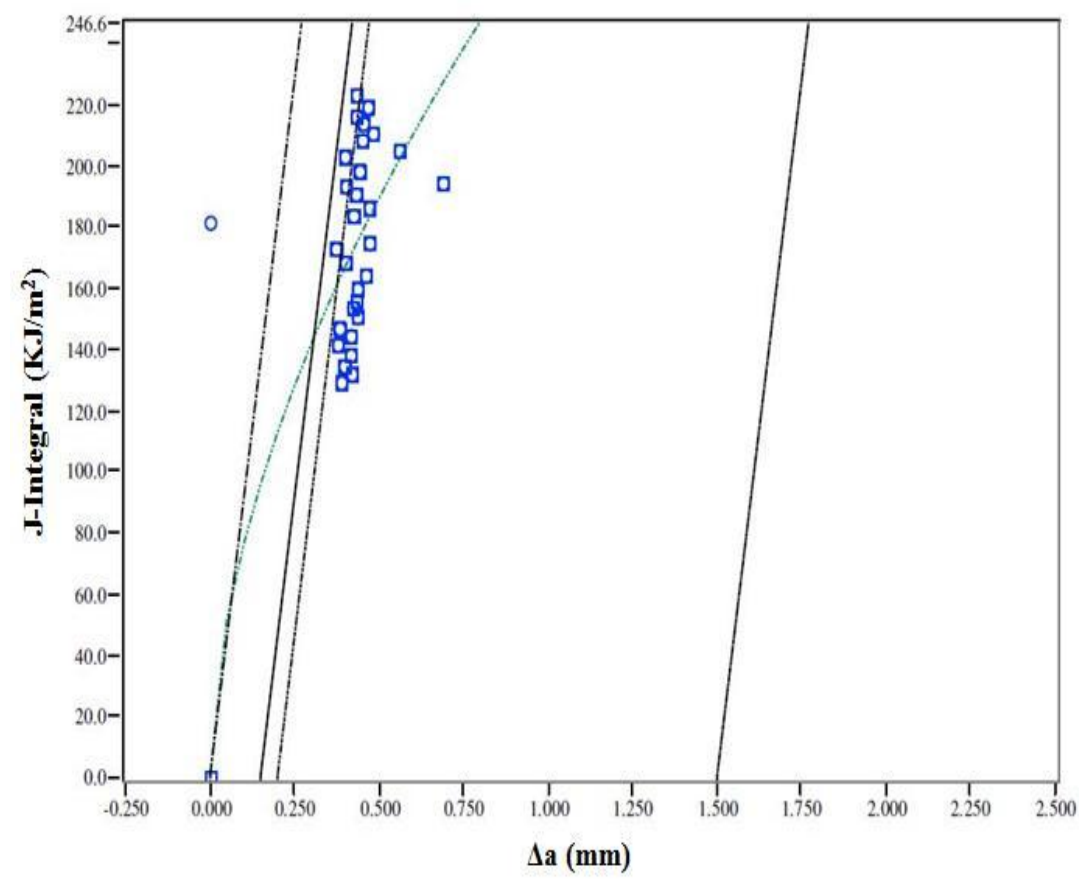

Alloy 617

Figure 8: J-Integral vs. $\Delta \mathrm{a}$ at Ambient Temperature

Table 3: $K_{1}$ and $\delta$ Values vs. Temperature

\begin{tabular}{lllll}
\hline \multirow{2}{*}{ Temperature $\left({ }^{\circ} \mathrm{C}\right)$} & Alloy 617 & \multicolumn{3}{l}{ Alloy 276 } \\
\cline { 2 - 5 } & $\mathrm{K}_{1 \mathrm{C}}(\mathrm{MPa} \sqrt{\mathrm{m}})$ & $\delta(\mathrm{mm})$ & $\mathrm{K}_{\mathrm{IC}}(\mathrm{MPa} \sqrt{\mathrm{m}})$ & $\delta(\mathrm{mm})$ \\
\hline Room Temperature & 193.7 & 0.20 & 189 & 0.20 \\
100 & 208.9 & 0.22 & 205.5 & 0.21 \\
200 & 216.4 & 0.23 & 213.7 & 0.22 \\
300 & 231.5 & 0.24 & 227.4 & 0.24 \\
\hline
\end{tabular}

\subsection{Equivalent $\mathrm{K}_{\mathrm{IC}}$ and $\mathrm{CTOD}$ values}

The fracture toughness values are estimated using the $\mathrm{J}$ integral approach. Table 3. shows equivalent $\mathrm{K}_{1 \mathrm{c}}$ and the CTOD values for Alloy 617 and Alloy 276. These values match with open literature. Further, the calculated $\delta$ values for alloy 617 were very close to a range in CTOD values (0.1 to 0.2) for an adequately tough material [17].

\subsection{Tearing modulus values}

The ASTM designation E 8-01 was used to establish the Young's modulus for Alloy 617. The tearing modulus for this alloy varies with temperature and is represented in a semi-logarithmic scale [18]. By averaging the ultimate tensile strength and yield strength the flow stress is obtained with the highest uncertainty between all conditions. Based on recent research [19] large stretch zone corresponds to large tearing moduli. The furnace setback limited the study to be conducted at a specific temperature range (up to $500^{\circ} \mathrm{C}$ ); however, the tearing modulus maintained to remain close in these temperature constraints resulting, in accurate results corresponding with the study. The values obtained show a high accuracy with the conducted study [19].

\subsection{Finite element analysis of experimental work}

Half CT specimen shown in Figure.10 has meshed with 1922 quadrilateral 2D solid elements in ANSYS. A load of 30 $\mathrm{kN}$ was applied at the inside surface of the specimen hole as shown with arrows. $30 \mathrm{kN}$ load was distributed equally over 15 nodes with each node subjected to $2 \mathrm{kN}$ force. A symmetric boundary condition is shown for the half specimen. Principal stress plots for alloy 276 at room temperature and at $400{ }^{\circ} \mathrm{C}$ are shown in Figures 11 and 12 respectively. As expected the plastic zone size at $400^{\circ} \mathrm{C}$ is larger compared to the plastic zone size at $30^{\circ} \mathrm{C}$. 


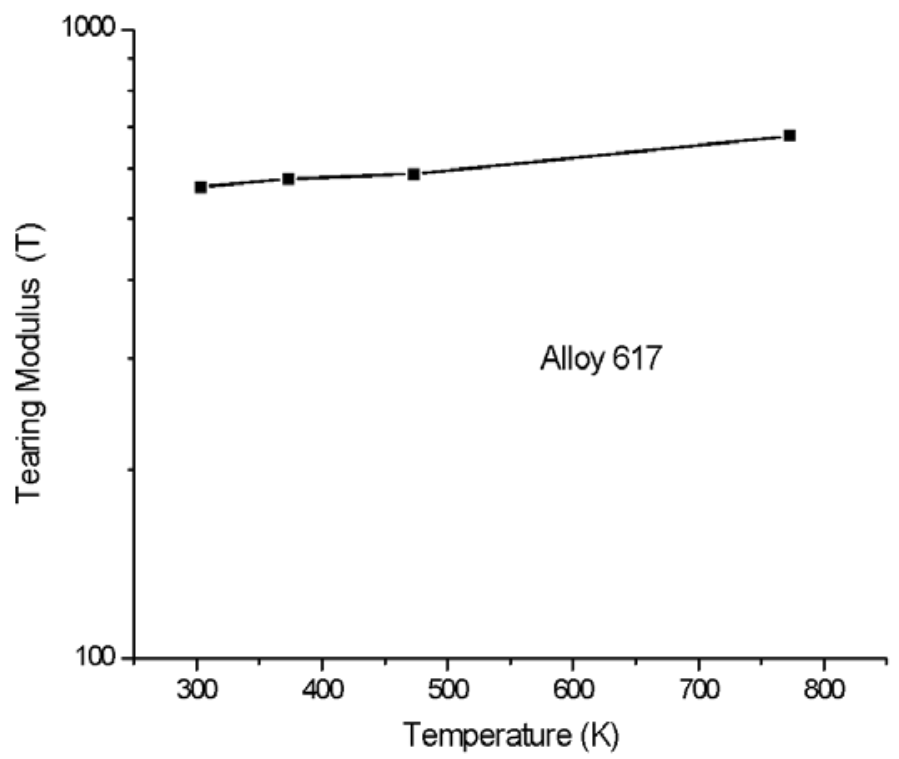

Figure 9: J-Integral vs. $\Delta \mathrm{a}$ at Ambient Temperature

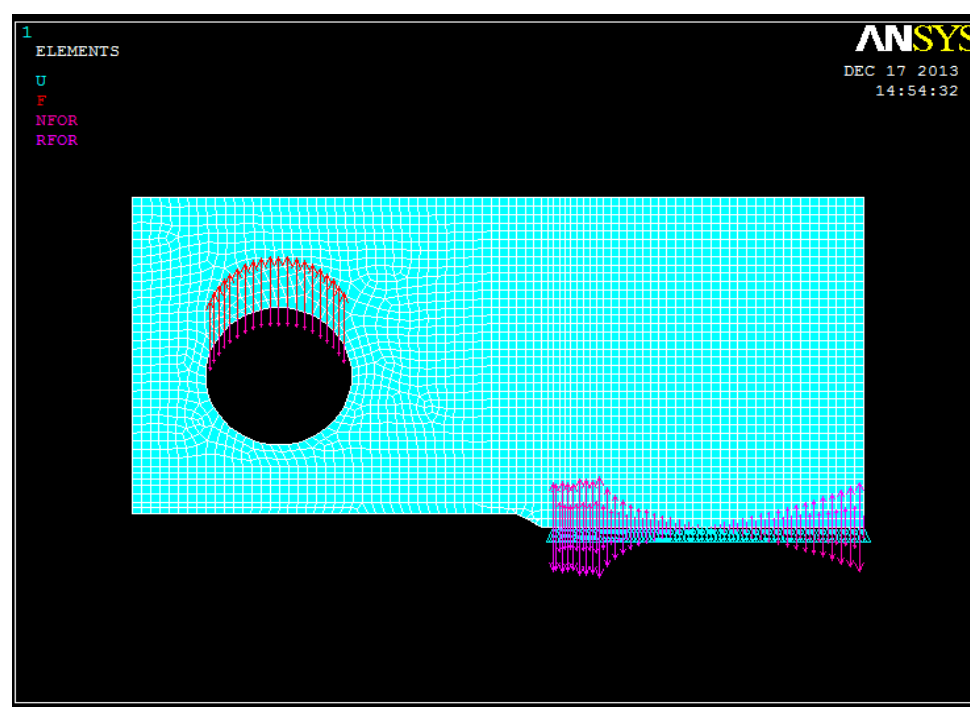

Figure 10: CT specimen mesh showing the loading and the symmetry boundary condition.

A total of 20 paths were defined around the crack tip for J Integral estimation in all simulations. The J Integral values for alloy 617 and alloy 276 at varying temperatures are shown in Fig.13 and Fig.14 respectively. It was observed that as the temperature increases the $J$ values do not converge in the near field paths due to an excessive drop in the yield stress and enhanced plasticity. An increase in J values was recorded for increasing temperatures [20] as shown in Fig.14. That also points out to the fact that the path independency of the $J$ integral could not be maintained at higher plasticity [21]. This is shown in Fig.14 where the J values do not converge easily to a single value but show a path dependency at $400^{\circ} \mathrm{C}$. Path independency for J integral was observed even until $500{ }^{\circ} \mathrm{C}$ for the alloy 617 but as the temperature reaches $400^{\circ} \mathrm{C}$ for alloy 276 the J values show path dependence. Cracking deformation behaviour in nickel-based superalloys with stress and strain characteristics are correlated by finite element analysis of microscopic and macroscopic structures [10]. 


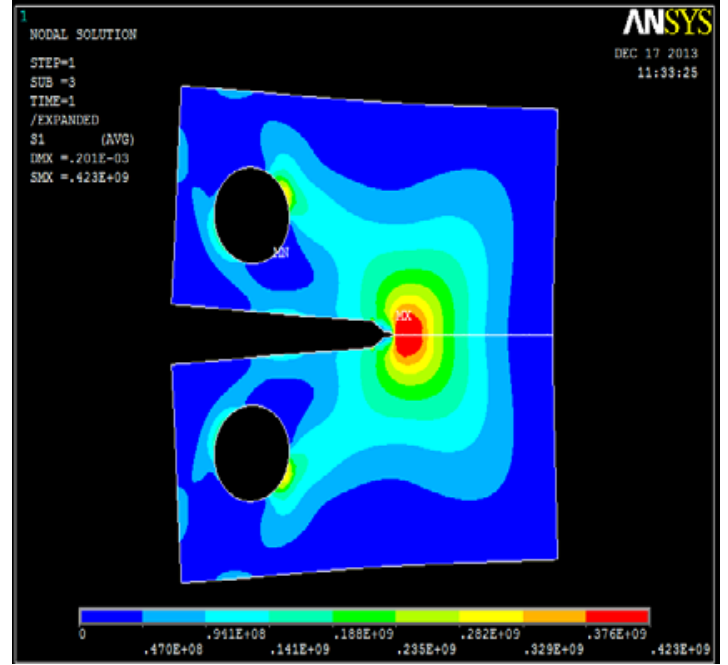

Figure 11: Principal stress distribution in CT specimen for Alloy 276 at $30^{\circ} \mathrm{C}$

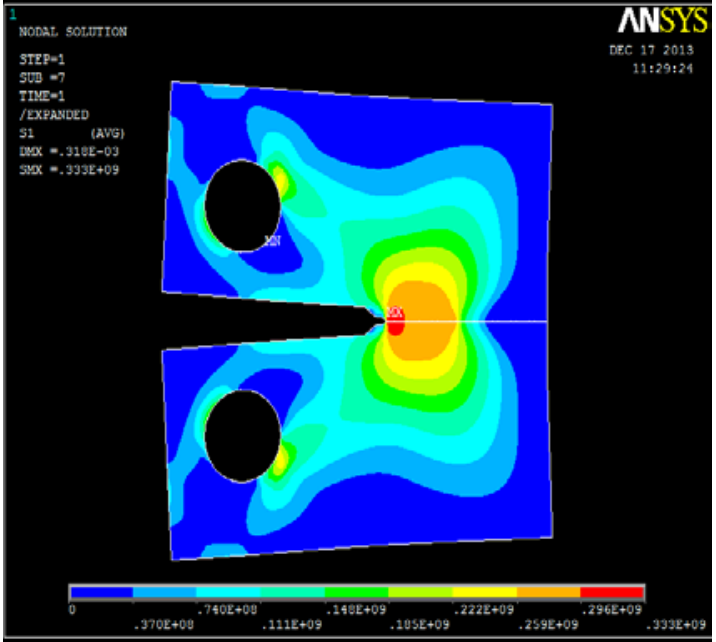

Figure 12: Principal stress distribution in $\mathrm{CT}$ specimen for Alloy 276 at $400^{\circ} \mathrm{C}$

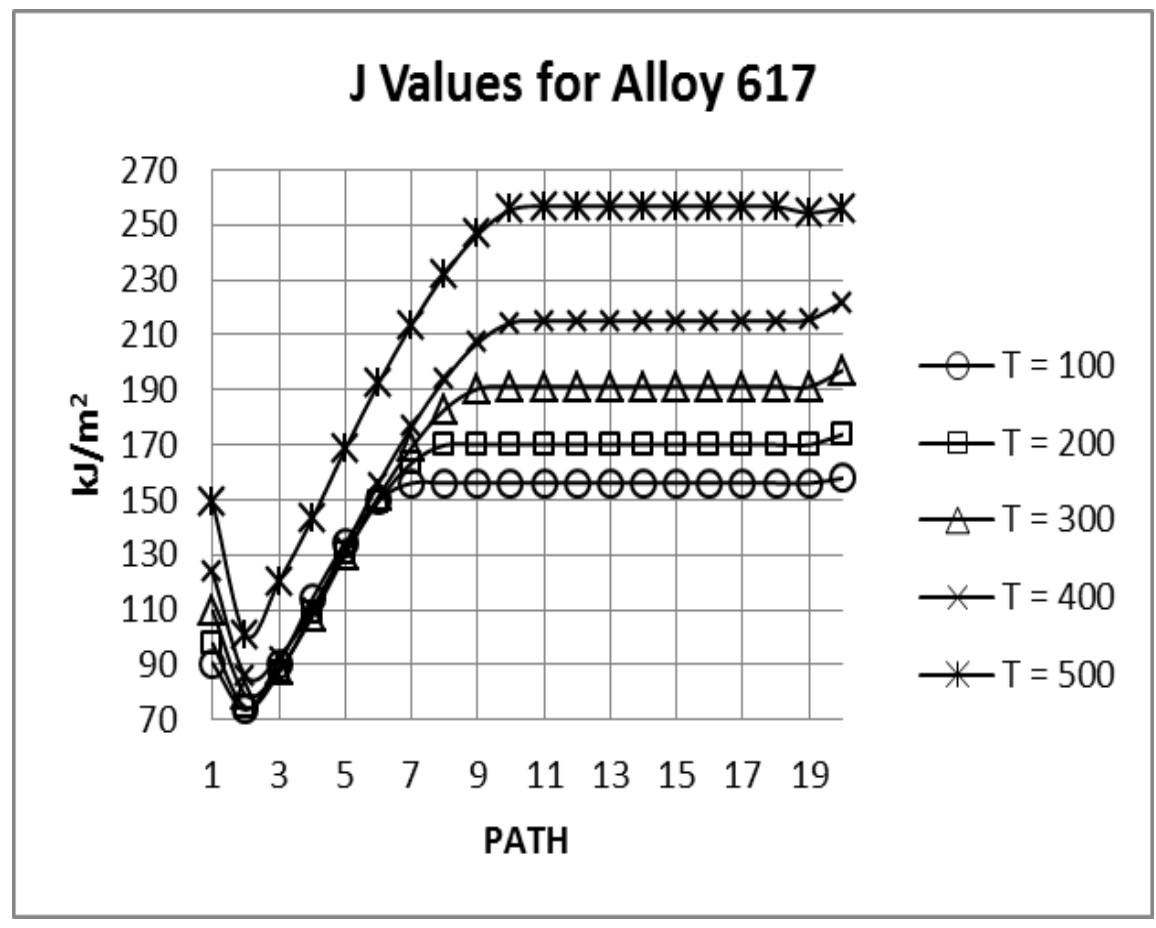

Figure 13: J Integral variation with increasing temperature for alloy 617.

\subsection{Fractographic Evaluations}

Figure 15 indicates the SEM micrographs of alloy 617 that were sampled and experimented at room temperature. Three different sections are illustrated by the micrographs each causing a change in morphology. Fatigue precracking results in mild striations in one region; however, the vivid striations are caused by loading and unloading sequences and the last region shows dimples on the surface which result from fast rupture. Changes in microstructure, as well as applied strain range due to high temperatures, causes a decline in fatigue life in Alloy 617 [22]. 


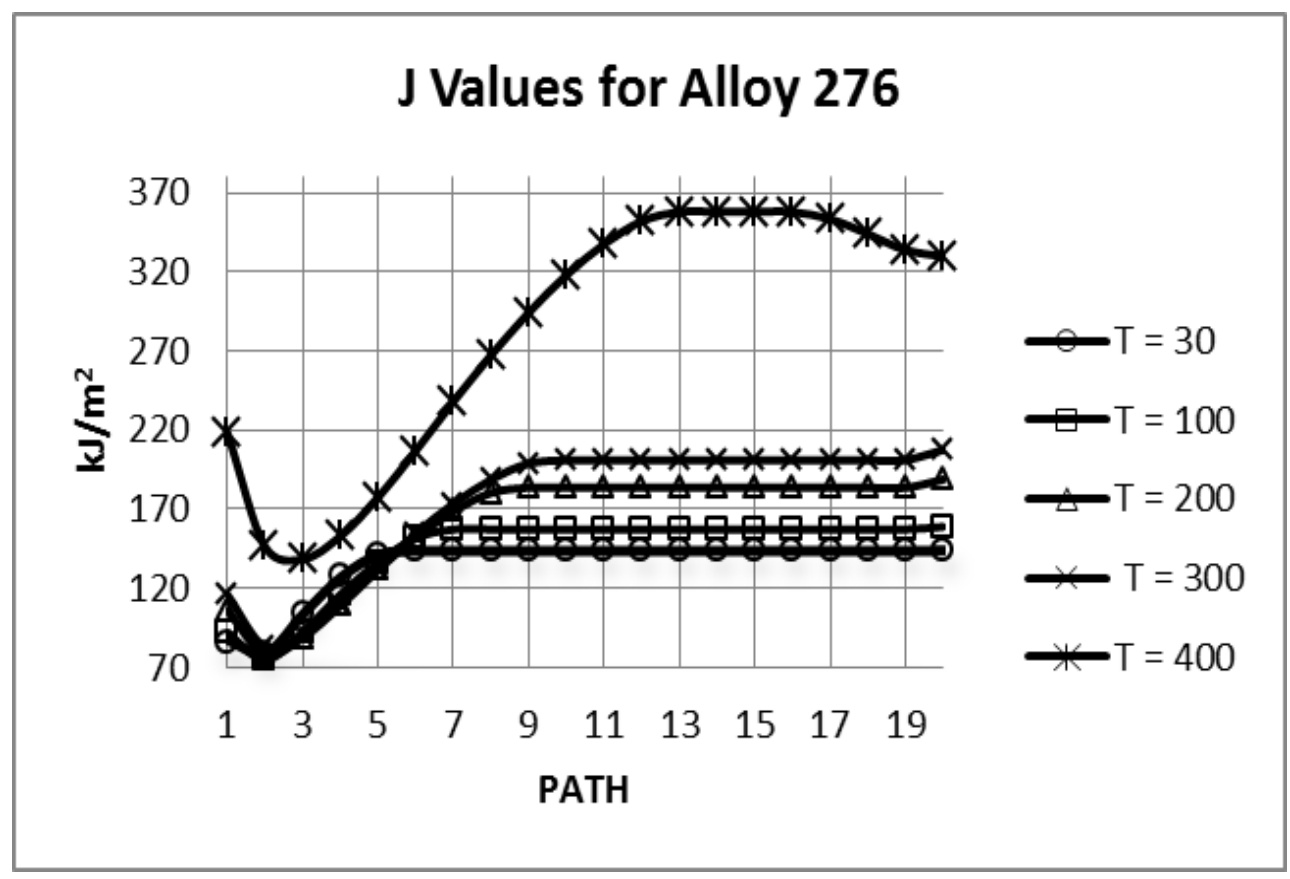

Figure14: J Integral variation with increasing temperature for alloy 276

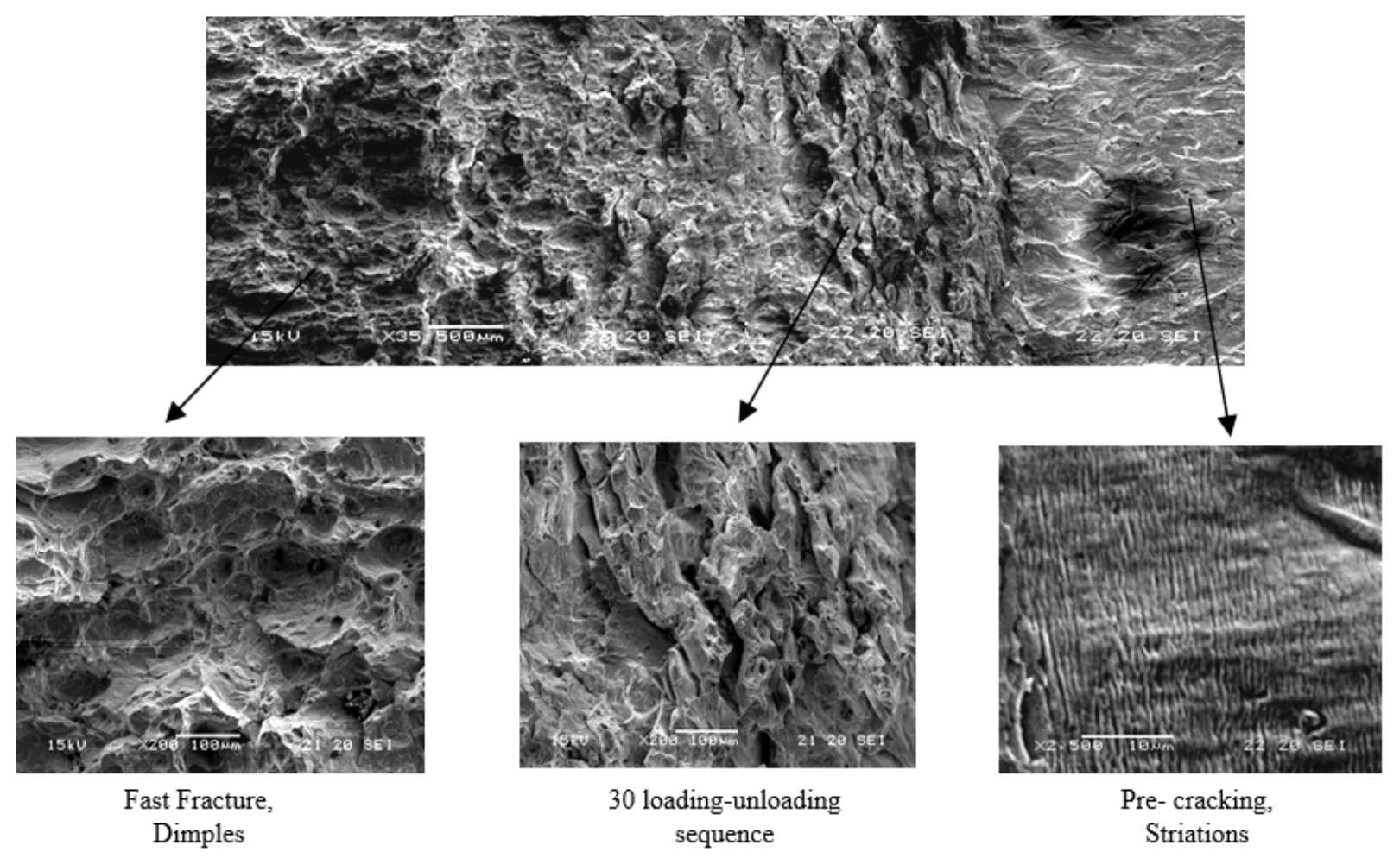

Figure 15: SEM micrographs of sampled specimens 


\section{CONCLUSIONS}

The focus of this study was on the evaluation of fracture toughness behaviour of Alloys 617 and 276 . The key results obtained from the investigation are summarized below.

1. The $J_{1 C}$ values fulfilled the legitimacy requirements dictated by the ASTM Designation E 813-1989.

2. The effect of temperature on $J_{1 C}$ value for Alloy 617 is not that much significant up to $500^{\circ} \mathrm{C}$. The reduction in the $\mathrm{J}_{1 \mathrm{C}}$ value from 200 to $500^{\circ} \mathrm{C}$ was minimal. Further, the tearing modulus was changed insignificantly along with the temperature as expected.

3. An abrupt increase is observed in the value of $\mathrm{J}_{1 \mathrm{C}}$ for Alloy 276 from $400^{\circ} \mathrm{C}$ temperature to $500^{\circ} \mathrm{C}$, due to enhanced plasticity and path dependency.

4. J values for both the alloys show path independency up to $300^{\circ} \mathrm{C}$ for an insignificant amount of plastic zone at the crack tip.

5. Experimental results of $\mathrm{J}$ values and path independency were validated by the finite element analysis in ANSIS.

6. Dimpled microstructures and striations are revealed from the fractographic evaluations of both broken $C T$ specimens.

\section{ACKNOWLEDGEMENT}

The authors would like to appreciate very much the experimental and analytical support from Department of Mechanical and Industrial Engineering at Ryerson University in doing this research.

\section{REFERENCES}

1. N. Dalili, A.Edrisy and R. Carriveau "A review of surface engineering issues critical to wind turbine performance" Renewable and Sustainable energy reviews, 13 (2009) 428-438.

2. Paul M. Mathias and Lloyd C. Brown "Thermodynamics of the Sulfur-lodine Cycle for Thermochemical Hydrogen Production" Japan March 2003, 68th Annual Meeting of the Society of Chemical Engineers, Japan The University of Tokyo

3. Akbari-Garakani, M., \& Mehdizadeh, M. (2011). Effect of long-term service exposure on microstructure and mechanical properties of alloy 617. Materials and Design, 32(5), 2695-2700. doi:10.1016/j.matdes.2011.01.017

4. Y. Sakai, T. Tanabe, T. Suzuki, H. Yoshida, "Corrosion Behavior of Inconel 617 in a Simulated HTGR Helium", Transactions of National Research Institute for Metals, vol. 27, 1985, pp. 20-27

5. U. Bruch, D. Schumacher, P. Ennis, E. Heesen, "Tensile and Impact Properties of Candidate Alloys for HighTemperature Gas-Cooled Reactor Applications”, Nuclear Technology, vol. 66, 1984, pp. 357-362

6. Ajit Roy, Muhammad H. Hasan, Joydeep Pal "Creep deformation of Nickel-base superalloys at different temperatures”, Materials science and Engineering: A 520 (2009) 184-188.

7. Yu, Q. M., Hou, N. X., \& Yue, Z. F. (2010). Finite element analysis of void growth behavior in nickel-based single crystal superalloys. Computational Materials Science, 48(3), 597-608. doi:10.1016/j.commatsci.2010.02.028

8. Vikram Marthandam, "Tensile Deformation, Toughness and Crack Propagation Studies of Alloy 617", Ph.D. Dissertation, Mechanical Engineering, April 10, 2008

9. "Wan, V. V. C., Jiang, J., MacLachlan, D. W., \& Dunne, F. P. E. (2016). Microstructure-sensitive fatigue crack nucleation in a polycrystalline ni superalloy. International Journal of Fatigue, 90, 181-190. doi:10.1016/j.ijfatigue.2016.04.013"

10. Mukai, Y., Kagawa, H., \& Okazaki, M. (2015). Finite element analysis on crack tip deformation behavior under mode-Il loading in single crystal superalloy. Key Engineering Materials, 665, 281-284.

11. Xiao Guang, $\mathrm{Zu}$ Han Lai, “ Realization of single specimen analytical method of $\mathrm{J}_{1 \mathrm{C}}$ determination by using compact tension loading”. Engineering Fracture Mechanics, Vol 34 No.5/6, pp 1013-1021, 1989

12. ASTM Designation E 399-1999. "Standard Test Method for Linear-Elastic Plane-Strain Fracture Toughness $K_{1 C}$ of Metallic Materials." American Society for Testing and Materials (ASTM) International

13. ASTM Designation E 813-1989. "Standard Test Method for $\mathrm{J}_{1 \mathrm{C}}$, A Measure of Fracture Toughness." American Society for Testing and Materials (ASTM) International.

14. Instron Corp. Fast Track 2 - $\mathrm{J}_{1 \mathrm{C}}$ Unloading Compliance Software.

15. Structural Integrity Associates Inc. "Nonlinear Fracture Toughness Testing." Technical Paper.

16. Perez, J.E., Ipiñaa, Yawnyb, A.A., Stukeb, R. \& Oliverb, C. Gonzalez. "Fracture Toughness in Metal Matrix Composites." Materials Research 3 (2000): 74-78.

17. Hertzberg, Richard W. Deformation and Fracture Mechanics of Engineering Materials. NY: John Wiley \& Sons, 1996.

18. ASTM Designation E 8-2001. "Standard Test Method for Tension Testing of Metallic Materials"

19. K. Krompholz, E.D. Grosser \& K.Ewert. "Determination of J-integral R-curve for Hastelloy X and Inconel 617 up to $1223 \mathrm{~K}$ using Potential Drop Technique” Materials Science and Engineering Technology, Volume 13, Issue 7, Page 236-244, July 1982. 
20. Hsiao-Hung Hsu, Yen-Chie Wu, Leu-Wen Tsay, Notch brittleness of Ti-15V-3Cr-3Al alloys, Materials Science and engineering A, 545 (2012) 20-25.

21. W. Brocks and I. Scheider, Numerical Aspects of the Path-Dependence of the J-Integral in Incremental Plasticity: How to calculate reliable J-values in FE analyses, Technical Note GKSS/WMS/01/08, internal report, Institut fur Werkstofforschung. (2001)

22. Dewa, R. T., Kim, S. J., Kim, W. G., \& Kim, E. S. (2017). Effect of strain range on the low cycle fatigue in alloy 617 at high temperature. Metals, 7(2), 54. doi:http://dx.doi.org.ezproxy.lib.ryerson.ca/10.3390/met7020054

23. Riveros, G. A. , Numerical evaluation of stress intensity factors (KI) J-integral approach. Coastal and Hydraulics Engineering Technical Note, ERDC/CHL CHETN-IX-16. (2006) Vicksburg, MS: U.S. Army Engineer Research and Development Center.

24. H Ching, C Liu, S Yen, FE calculations of J-Integrals in a constrained elastomeric disk with crack surface pressure and isothermal load, Air Force Research Laboratory (AFMC),AFRL/PRSM,10 E. Saturn Blvd.,Edwards (2004) AFB,CA,93524-7680

25. “CTOD Testing." May 25, 2009. <http://www.twi.co.uk/content/jk76.html>. 